\title{
SSC-ASSOCIATED MAGNETIC VARIATIONS AT THE GEOSYNCHRONOUS ALTITUDE
}

\author{
Masayuki Kuwashima, Satoru Tsunomura \\ Kakioka Magnetic Observatory, 595, Kakioka, Yasato-machi, \\ Niihari-gun, Ibaraki 315-01
}

and

Hiroshi FUKUNISHI

National Institute of Polar Research, 9-10, Kaga 1-chome, Itabashi-ku, Tokyo 173

\begin{abstract}
SSC events at the geosynchronous altitude have been studied using the data obtained at the geosynchronous satellite, SMS/GOES, as well as the data obtained on the ground for the period from 1976 to 1980. In the compressional component (parallel to the ambient magnetic field direction), the SSC amplitude is very large in the noonside, while it becomes smaller with increasing distance from the noonside and is very small or none in the midnightside. In the transverse component (east-west direction), the direction of the initial movement of Psc changes drastically across the noon and the midnight. The direction is eastward in the morningside, while it is westward in the eveningside. These observational results will be examined quantitatively in the present study.
\end{abstract}

\section{Introduction}

The storm sudden commencement (SSC) of a geomagnetic storm was attributed by Chapman and Ferraro (1931) to a compression of the geomagnetic field by a highspeed stream of plasma, which may be generated by a solar flare and propagates through the interplanetary space. Many experimental studies have been carried out using the data obtained on the ground-based stations (NaGata and ABE, 1955; OBAYASH and JACOBS, 1957; Matsushita, 1960; Wilson and Sugiura, 1961; Sano, 1962; Nishida and JACOBS, 1962a, b; ONDOH, 1963; SANO, 1964). From the theoretical standpoint, the hydromagnetic descriptions for SSC have been given by WILSON and SugIURA (1961), Tamao (1964, 1975) and Nishida (1964, 1978). Recently, Araki (1977) and Araki and Allen (1982) studied details of the global distribution of SSC and their relationship to the magnetosphere-ionosphere coupling.

It is also well known that a damped-type magnetic pulsation (Psc) appears in association with SSC (SAIto and MAtSuShita, 1967; Kuwashima, 1972; KaUfman and Walker, 1974). Namikawa and Matsushita (1970) interpreted Psc in terms of the interaction between pulsations and the current-free magnetospheric convection. Chen and Hasegawa (1974) proposed that the field line resonance could be excited by the impulsive driving force if there is a sharp discontinuity of the plasma parameters. However, a mechanism driving Psc has not been yet clarified in the present stage. 
Characteristics of SSC in the magnetosphere have also not been studied sufficiently compared with those on the ground. GosLING et al. (1967), OGILVIE et al. (1968) and BurLagA and OGILVIE (1969) observed the solar plasma, temperature and magnetic field in the interplanetary space during SSC. They confirmed that the SSC events were closely associated with hydromagnetic shocks or tangential discontinuities in the interplanetary space. SUGIURA et al. (1968) observed that SSC amplitude increases in the magnetotail, and they tried to interpret the observational result by an additional magnetic flux swept back from the magnetosphere by the solar wind. Distributions of the amplitude and the rise time of SSC in the magnetosphere were studied by ONDOH (1970) using the data obtained by the OGO 3 and 5 satellites. Recently, WILKEN et al. (1982) studied a single SSC event which occurred on July 29, 1977, with the measurements from a total of six satellites at the geosynchronous orbit and in the interplanetary space.

As mentioned above, there were several studies concerning the SSC event in the magnetosphere. However, the relationship of the SSC signatures in the magnetosphere with those on the ground have not been always clarified. At the middle- and lowlatitude stations on the ground, the almost uniform northward fields (the amplitude of SSC) are always observed in association with SSC without dependency on the occurrence local time. It is an important problem whether such a tendency mentioned above occurs in the magnetosphere or not. In the present paper, the SSCassociated magnetic variations will be studied based on the data obtained at the multiple geosynchronous satellites as well as the data obtained at the ground-based station.

\section{Data Sources}

The Synchronous Meteorological Satellites (SMS) and the Geostationary Operational Environmental Satellites (GOES) traveled in the geosynchronous orbit (6.67 Earth radii) carrying twin fluxgate spinning magnetometers (GRUBB, 1975). During the period from 1976 to 1980 , two or three satellites were located in the geosynchronous orbit and operated the observations simultaneously (ARTHUR, 1979). Those geosynchronous satellites were located in the longitudinal range from $75^{\circ} \mathrm{W}$ to $135^{\circ} \mathrm{W}$. The spinning sensor allowed reconstruction of the Earth's magnetic field in three components at the geosynchronous altitude. One component, $H_{\mathrm{P}}$, was parallel to the satellite spin axis, which was itself perpendicular to the satellite's orbital plane. The $H_{\mathrm{E}}$ component lied perpendicular to the satellite spin axis and parallel to the satelliteEarth center line. $\quad H_{\mathrm{N}}$ was perpendicular to both the satellite spin axis and the satellite-Earth center line, and it pointed westward. The basic sensitivity was $0.2 \mathrm{nT}$ and the time resolution was $3.06 \mathrm{~s}$. In the present study, analog data plotted with every one-hour interval have been mainly used.

The normal-run magnetograms obtained on the ground at the middle- and lowlatitudes have been used for identification of an SSC event. Used stations are Kakioka $\left(26.0^{\circ}\right.$ in the geomagnetic latitude and $206.0^{\circ}$ in the geomagnetic longitude), Hermanus $\left(-33.7^{\circ}, 81.7^{\circ}\right)$, San Juan $\left(29.9^{\circ}, 3.2^{\circ}\right)$ and Honolulu $\left(21.1^{\circ}, 266.5^{\circ}\right) .165$ SSC events were identified during the period from 1976 to 1980 . Rapid-run magnetograms at Kakioka and Hermanus have been also used for identification of an onset time of SSC. 
The field lines which intersect the geosynchronous altitude in the magnetosphere are expected to be anchored in the auroral region $(L=6 \sim 7)$ on the ground. Rapidrun magnetogram at Syowa Station $(L \sim 6.1)$ in Antarctica has been used for the comparison of SSC between the magnetosphere and the ground.

\section{Local-Time Dependence of SSC Amplitude at the Geosynchronous Altitude}

Examples of the simultaneous appearance of SSC at the two geosynchronous satellites (GOES 2 and 3) are shown in Figs. la and $1 \mathrm{~b}$. As shown in these figures, signatures of SSC at the geosynchronous altitude are observed more dominantly in the compressional component ( $H_{\mathrm{P}}$-component). In Fig. la, the onset of SSC was estimated to be about 1926 UT on August 18, 1980, when the satellites were located in the morning-noon hours. Local times of GOES 2 and 3 at the SSC onset were 1226 and 1026, while the amplitudes of SSC (in the compressional component) were 51.0 and $32.6 \mathrm{nT}$, respectively. The result from Fig. la indicates that the amplitude of SSC at the geosynchronous altitude increases as the local time of the satellite closes to the noon. Similar tendency can be found in the SSC event shown in Fig. 1b, where the onset of SSC was estimated to be about 2305 UT on July 3, 1978. At this time, the satellites were located in the afternoon-evening hours. Local times of GOES 2 and 3 at the SSC onset were 1805 and 1525, while the amplitudes of SSC were 18.0 and $28.9 \mathrm{nT}$, respectively. The amplitude of SSC increases as the local time of the satellite closes to the noon, in this case too.

Local-time dependence of the amplitude of SSC is studied statistically based on the SSC events which were observed simultaneously at the two geosynchronous satellites during the period of 1978-1980. 32 SSC events were simultaneously observed at the two satellites during the period. Among the 32 SSC events, three events were observed when one of the two satellite was located in the midnight hours (22-02 LT). Concerning these three events, there was not any SSC signature (increasing of the compressional component) at the satellites which were located in the midnight. Moreover, two of these events showed a decrease of the compressional component contrary to the increase as shown in Figs. la and $1 \mathrm{~b}$. Though important information might be included in the decrease of the compressional component, the study of these decreasing events is reserved for future in the present stage. So 29 increasing events are studied statistically. The amplitude of SSC at the geosynchronous altitude is normalized using the average amplitude of SSC at the low-latitude stations on the ground. The normalized amplitude $\left(b_{\mathrm{n}}\right)$ is given by

$$
b_{\mathrm{n}}=\frac{b}{b_{\mathrm{g}}} \mathrm{nT} \text {, }
$$

where $b$ is the observed amplitude at the geosynchronous altitude, while $b_{\mathrm{g}}$ is the average amplitude on the ground which is calculated by averaging the amplitudes of the $\mathrm{H}$ component at Kakioka, Honolulu, San Juan and Hermanus. Two normalized amplitudes were calculated corresponding to the two geosynchronous satellites for each SSC event, and the results are summarized in Fig. 2 . In the figure, the calculated 

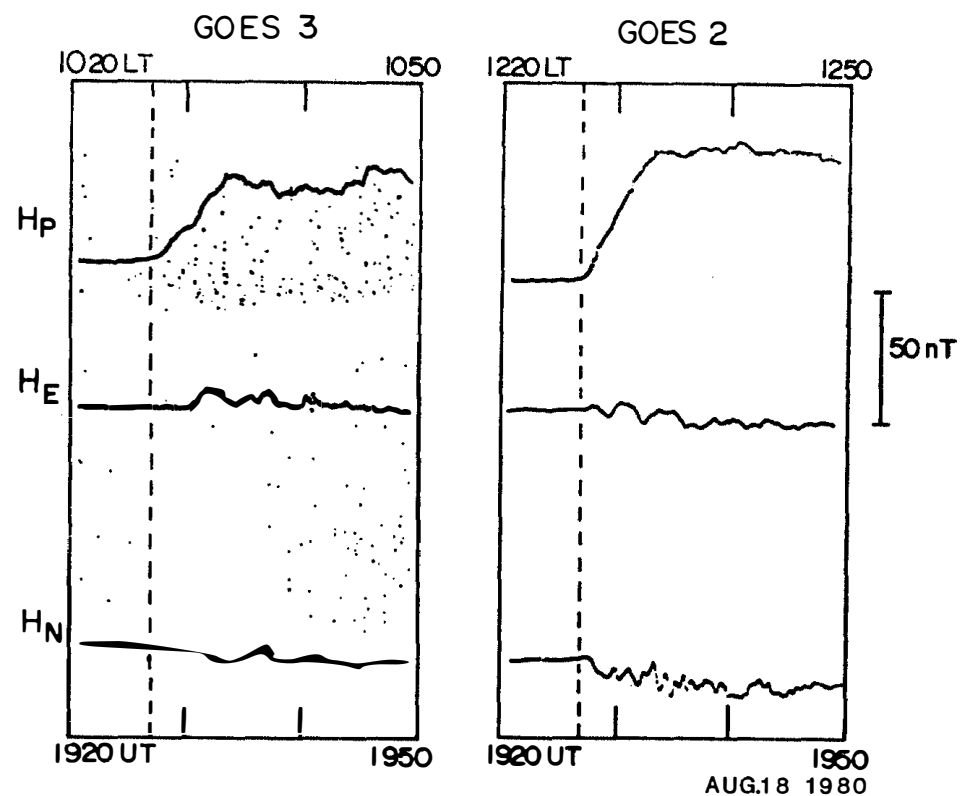

Fig. 1a. An example of the SSC events observed at the geosynchronous altitude in the morning hours. Local times of GOES 2 and 3 at the SSC onset were 1226 and 1026, while the amplitudes of SSC in the compressional component $\left(H_{\mathrm{P}}\right)$ were 51.0 and $32.6 \mathrm{nT}$, respectively.
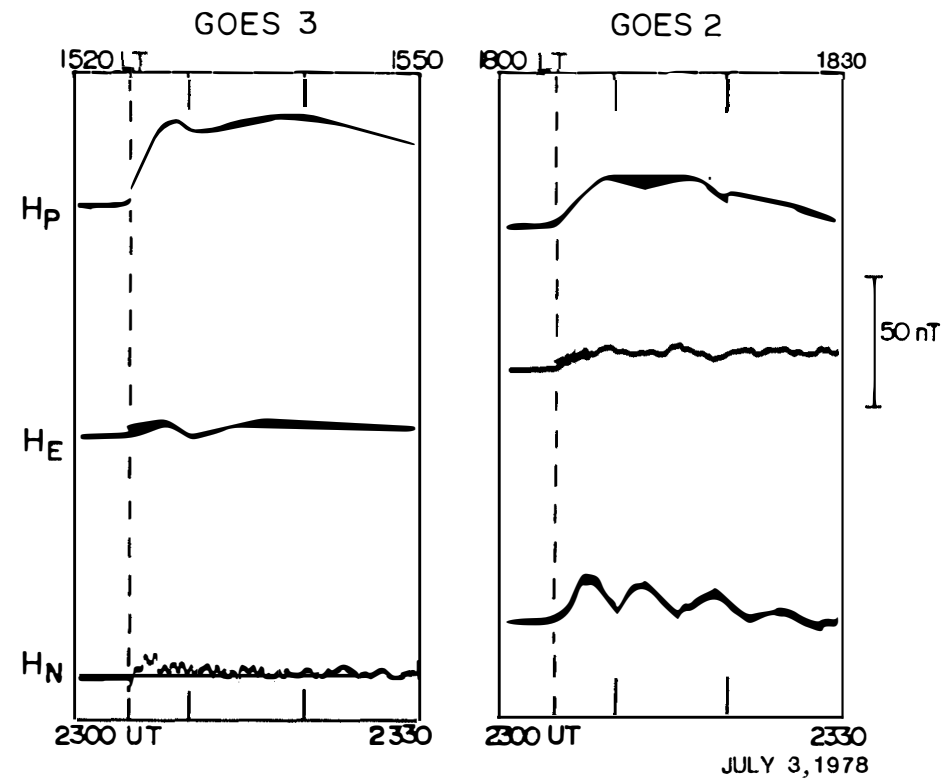

Fig. 1b. An example of the SSC events observed at the geosynchronous altitude in the evening hours. Local times of GOES 2 and 3 at the SSC onset were 1805 and 1525, while the amplitudes of SSC were 18.0 and $28.9 n T$, respectively.

normalized amplitude of SSC was presented by means of the common logarithmic function (ordinate), and the occurrence local time (abscissa). It is clearly found that the amplitude of SSC at the geosynchronous altitude shows a remarkably conspicuous local time dependence. Namely, the amplitude becomes larger as the local time of the satellite closes to the noon (12 LT). On the other hand, the amplitude is very 


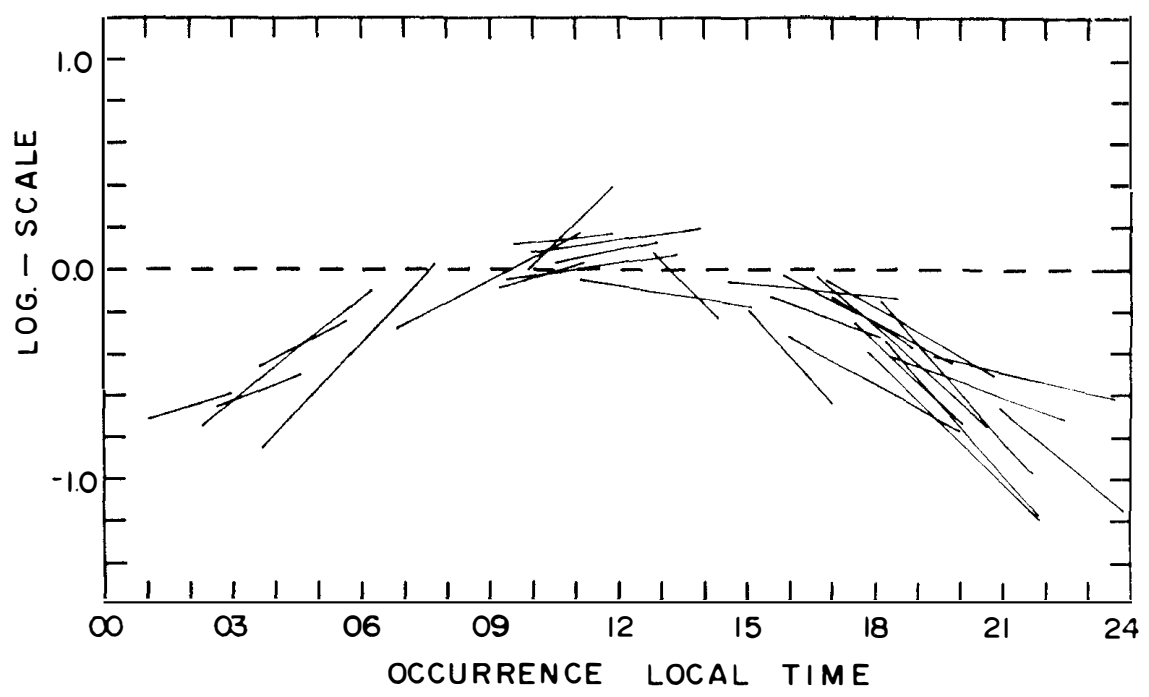

Fig. 2. Local-time dependence of the normalized amplitude of SSC at the geosynchronous altitude.

small when the satellite is located in the midnight hours. Such local time dependency as shown in Fig. 2 has not been found on the ground-based middle- and low-latitude stations, where the amplitudes of SSC are nearly similar without dependency on the occurrence local time (NiSHIDA and JACOBS, 1962a; KuwASHIMA et al., 1984). The evidence of the local-time dependence shown in Fig. 2 suggests that the SSC phenomena could not be simply interpreted by the compression of the whole magnetosphere. This problem will be further discussed in Section 6 .

\section{The Onset of SSC at the Geosynchronous Altitude}

SSC propagates through the magnetosphere in the compressional mode. In order to study the propagation mechanism of SSC in the magnetosphere, it is necessary to clarify the local-time dependency of the SSC onset at the geosynchronous altitude. On the ground, the onset of SSC is observed almost simultaneously within one minute over the whole world (NiSHIDA and JACOBS, 1962a). So, an SSC onset time determined from the ground-based stations is used as a reference time in the study on the local-time dependency of the SSC onset at the geosynchronous altitude. The SSC onset time on the ground is determined using the rapid-run magnetograms (chart speed is $6 \mathrm{~mm} / \mathrm{min}$ ) at the low-latitude stations, Memambetsu, Japan and Hermanus, South Africa. Typical examples of the comparison of the SSC onset time between the ground and the geosynchronous altitude are shown in Figs. 3a, 3b and $3 \mathrm{c}$, where the SSC onset time on the ground is indicated by the dotted line. In the SSC event on June 14, 1978 shown in Fig. 3a, the onset on the ground was $~ 1211$ UT, while the onset at the geosynchronous altitude was also $\sim 1211$ UT. In the example shown in Fig. 3a, the geosynchronous satellite was located in the morningside $(\sim 0700$ LT) and the onset of SSC was almost simultaneous with that on the ground. In the example shown in Fig. 3b, the satellite was located in the midnightside and the SSC onset time ( 0828 UT on March 22, 1979) was about two minutes later than that on 


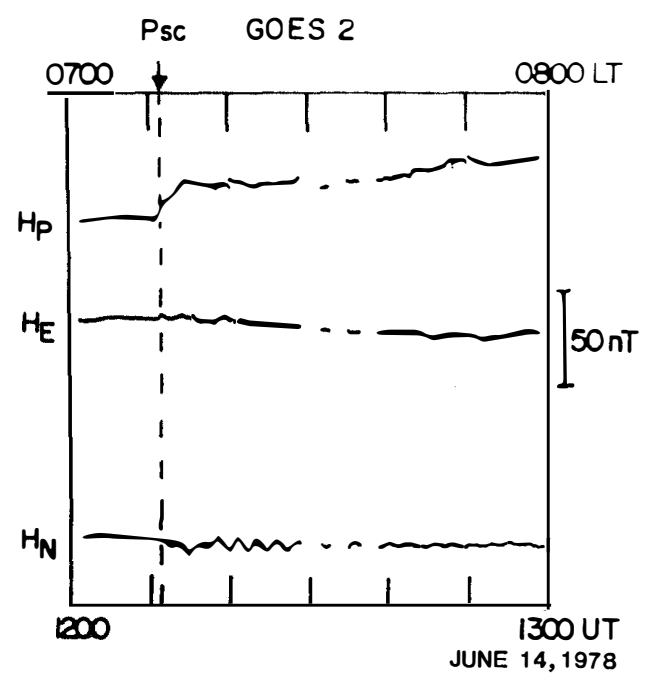

Fig. 3a.

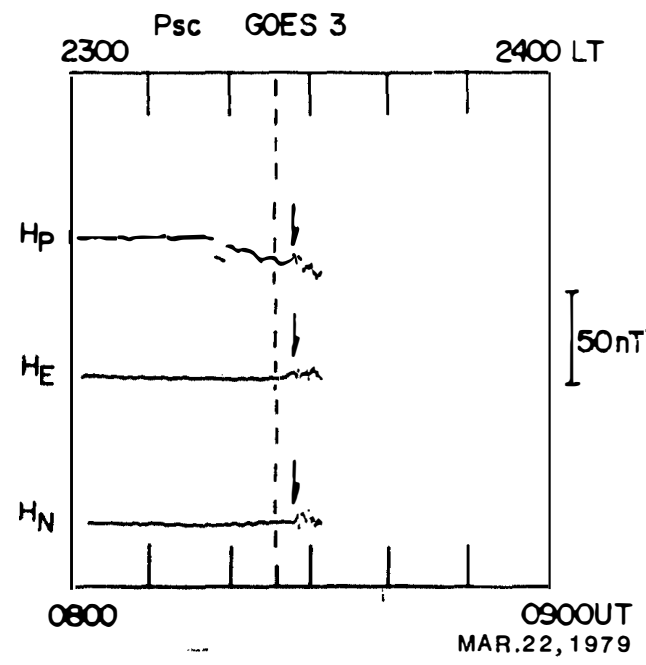

Fig. $3 b$.

GOES 1

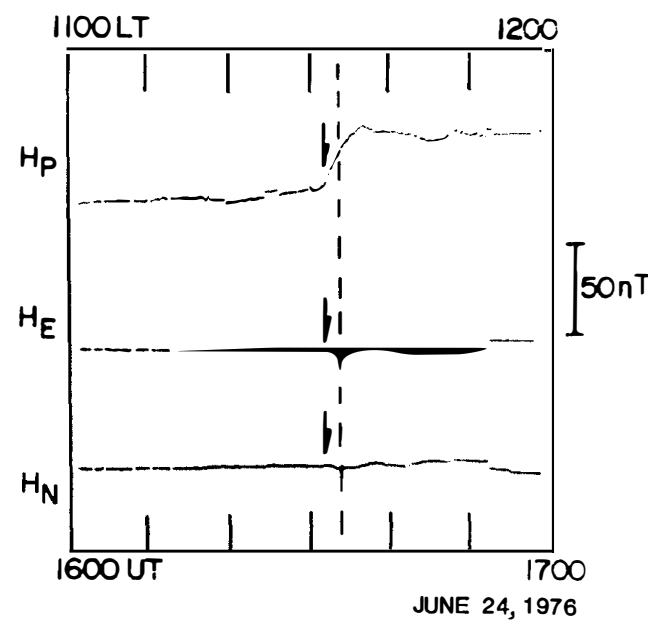

Fig. 3c.

Fig. 3. The SSC event observed at the geosynchronous altitude in the morningside (a), midnightside (b) and noonside $(c)$. The dotted line indicates the onset of SSC on the ground.

the ground $(\sim 0826 \mathrm{UT})$. On the other hand, in the example shown in Fig. $3 \mathrm{c}$, the satellite was located in the noonside and the SSC onset time ( $\sim 1632$ UT on June 24, 1976) was one minute faster than that on the ground $(\sim 1633$ UT). The results shown in Figs. 3a, 3b and 3c suggest that the onset time of SSC at the geosynchronous altitude depends on the local time of the satellite. Such the tendency will be confirmed statistically as summarized in Fig. 4. In the figure, the time differences of the SSC onset at the geosynchronous altitude to that on the ground are presented using the coordinates of the occurrence probability and occurrence local time. It is clarified in Fig. 4 that the SSC onset time at the geosynchronous altitude is faster than that on the ground about one minute in the noonside, while it is delayed with increasing distance from the noonside, and the onset time is one or two minutes later than that on the ground when the satellite is located in the midnightside. The tendency mentioned above will be further discussed in Section 6 . 


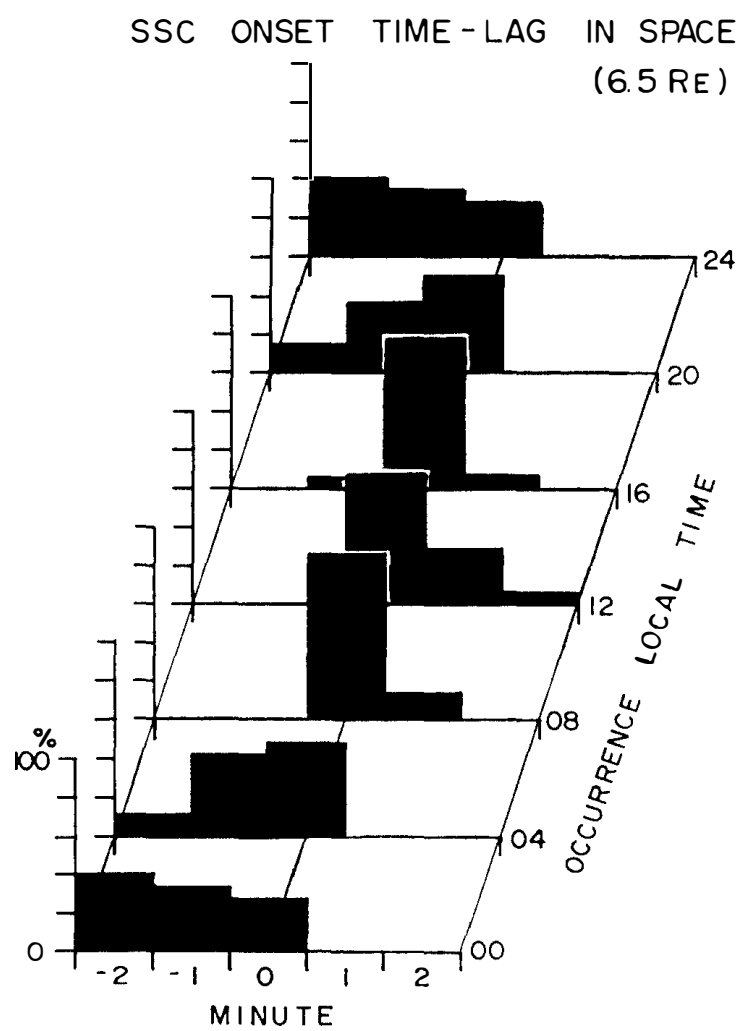

Fig. 4. Time difference of the onset of SSC between the geosynchronous altitude and the ground. The start of SSC at the geosynchronous altitude is about one minute faster than that on the ground in the noon $(\sim 12 L T)$, while it is about $\sim$ two minutes later in the midnight $(\sim 00 \mathrm{LT})$.

\section{Initial Movement of Psc at the Geosynchronous Altitude and in the Conjugate Region on the Ground}

It is found in the present study that damped-type pulsations (Psc) are often associated with SSC at the geosynchronous altitude. The typical Psc shows a dominant oscillation in the components perpendicular to the local magnetic field direction, and especially shows more dominant oscillation in the east-west $\left(H_{\mathrm{N}}\right)$ component as shown in Fig. 5. Psc is observed without dependency on the position of the satellite. The period of Psc is in the range of Psc 2-3 (a few tens of seconds) when the satellite is located in the noonside, while it becomes longer with increasing distance from the noonside, and it is in the range of Psc 4-5 (several hundreds seconds) when the satellites is located in the evening-midnightsides or in the morning-midnightsides. The period of the Psc oscillation will be related with the magnetic field configuration and the plasma distribution around the geosynchronous altitude in the magnetosphere. The conspicuous local-time dependence of the period of Psc as mentioned above is a very important phenomenon to clarify the state of the magnetosphere.

In addition to the local-time dependence of the period of Psc, the initial movement of Psc also shows a conspicuous local-time dependence at the geosynchronous altitude. In the SSC event on April 30, 1978, the onset time of SSC was determined at about 0951 UT, while the Psc oscillation with the period of $\sim 180 \mathrm{~s}$ was observed 


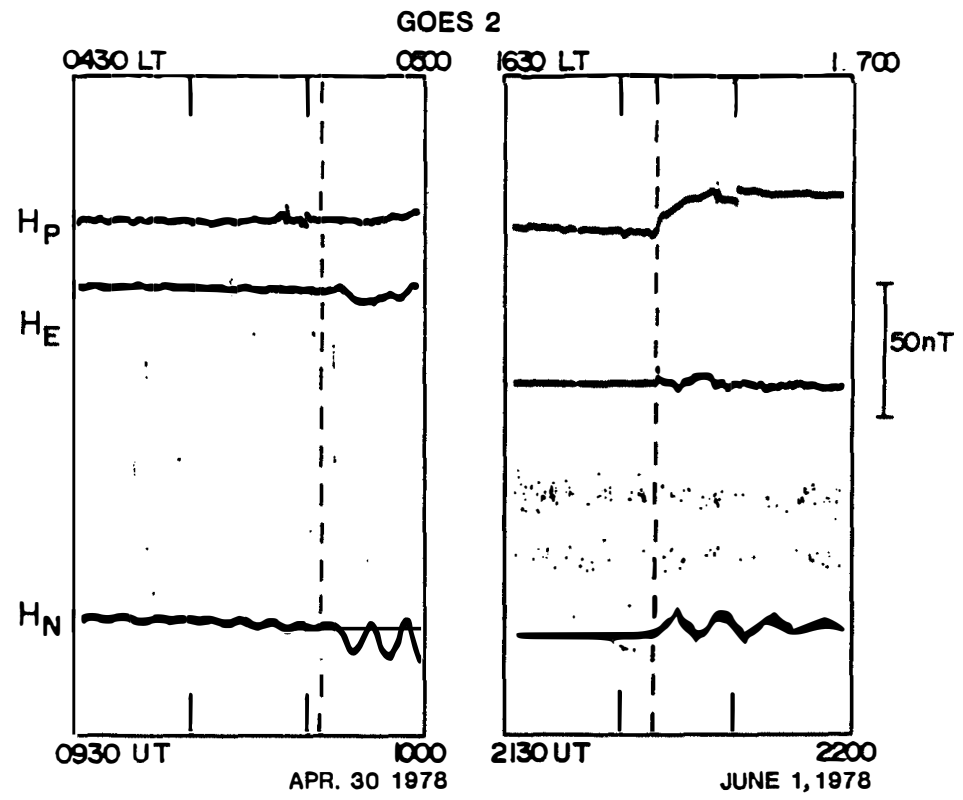

Fig. 5. The SSC events observed at the geosynchronous altitude in the morningside (left-hand panel) and in the eveningside (right-hand panel). Psc oscillations are dominant in the east-west component $\left(H_{N}\right)$. The direction of the initial movement of Psc is eastwardin the morningside, while it is westward in the eveningside.

dominantly in the east-west component as shown in the left-hand side of Fig. 5. In this case, the direction of the initial movement of Psc was eastward, while the satellite was located in the morningside ( $\sim 0450$ LT). In the SSC event on June 1, 1978, the onset time of SSC was determined at about 2143 UT, while the Psc oscillation with the period of $\sim 240 \mathrm{~s}$ was observed dominantly in the east-west component as shown in the right-hand side of Fig. 5. In this case, the direction of the initial movement

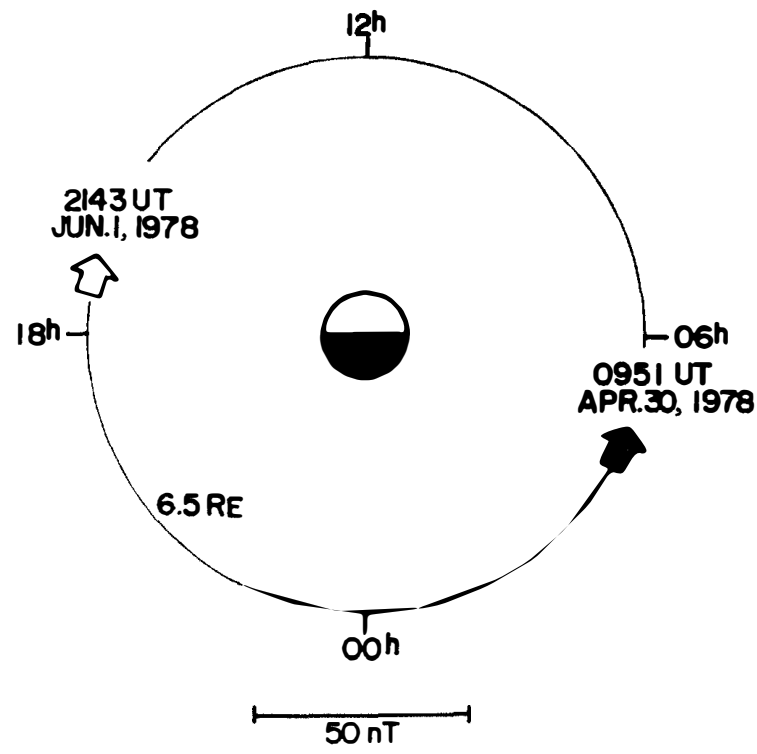

Fig. 6. The initial movement of the Psc events which are illustrated in Fig. 5.

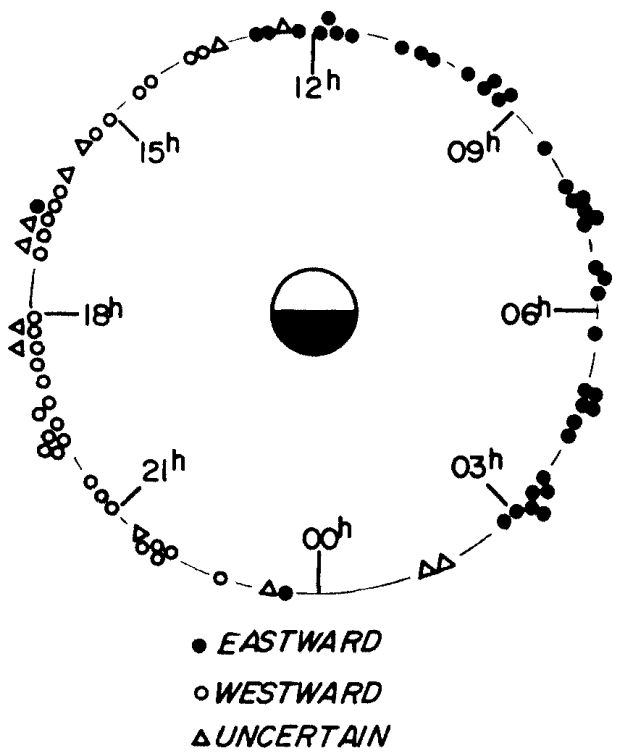

Fig. 7. The distribution of the direction of the initial movement of Psc at the geosynchronous altitude. 
of Psc was westward, and the satellite was located in the eveningside ( 1640 LT). The results from Fig. 5 suggest the direction of the initial movements of Psc at the geosynchronous altitude is eastward in the morningside, while westward in the eveningside as illustrated in Fig. 6. The tendency mentioned above has been confirmed statistically as shown in Fig. 7, where the initial movement of Psc in the eastwest component changes across both the noon and midnight at the geosynchronous altitude.

From the hydromagnetic standpoint, the magnetic perturbation perpendicular to the local magnetic field direction must be related to the Alfvén wave which propagates along the magnetic field line. Therefore, the tendency shown in Fig. 7 brings about a question how the hydromagnetic perturbation at the geosynchronous altitude shown in Fig. 7 is related to those on the ground. The field lines which intersect the equatorial plane at the geosynchronous altitude $\left(\sim 6.5 R_{\mathrm{E}}\right)$ might be anchored in the auroral region $(L=6 \sim 7)$ on the ground. In the present study, the behavior of the initial movement of Psc in the auroral region is studied using the rapid-run magnetogram at Syowa Station $(L \sim 6.1)$. The local time at Syowa Station (MLT=UT) is
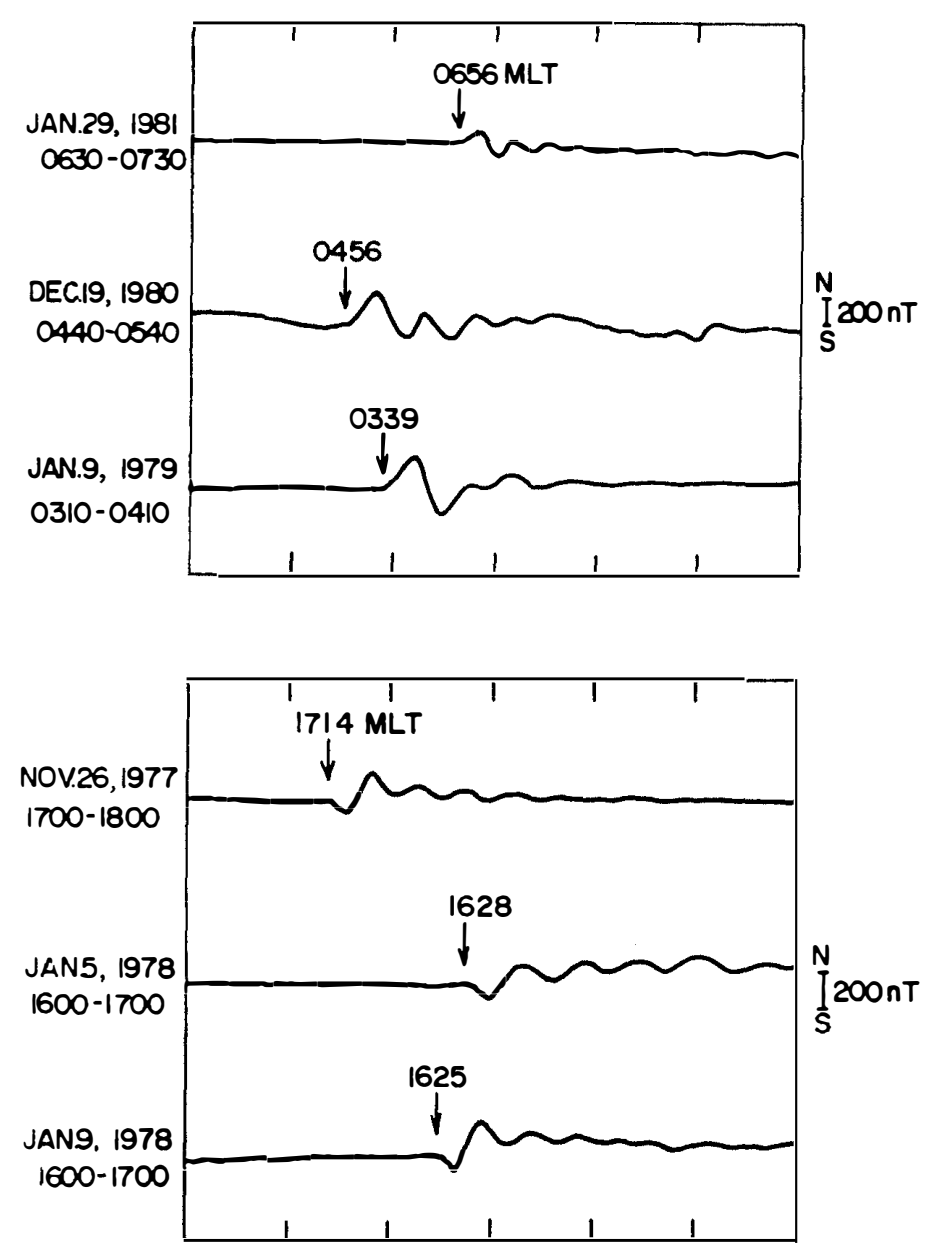

Fig. 8. Examples of Psc observed at Syowa Station (L 6.1) in Antarctica. The direction of the initial movement of Psc is northward in the morningside (upper panel), while it is southward in the eveningside (lower panel). 


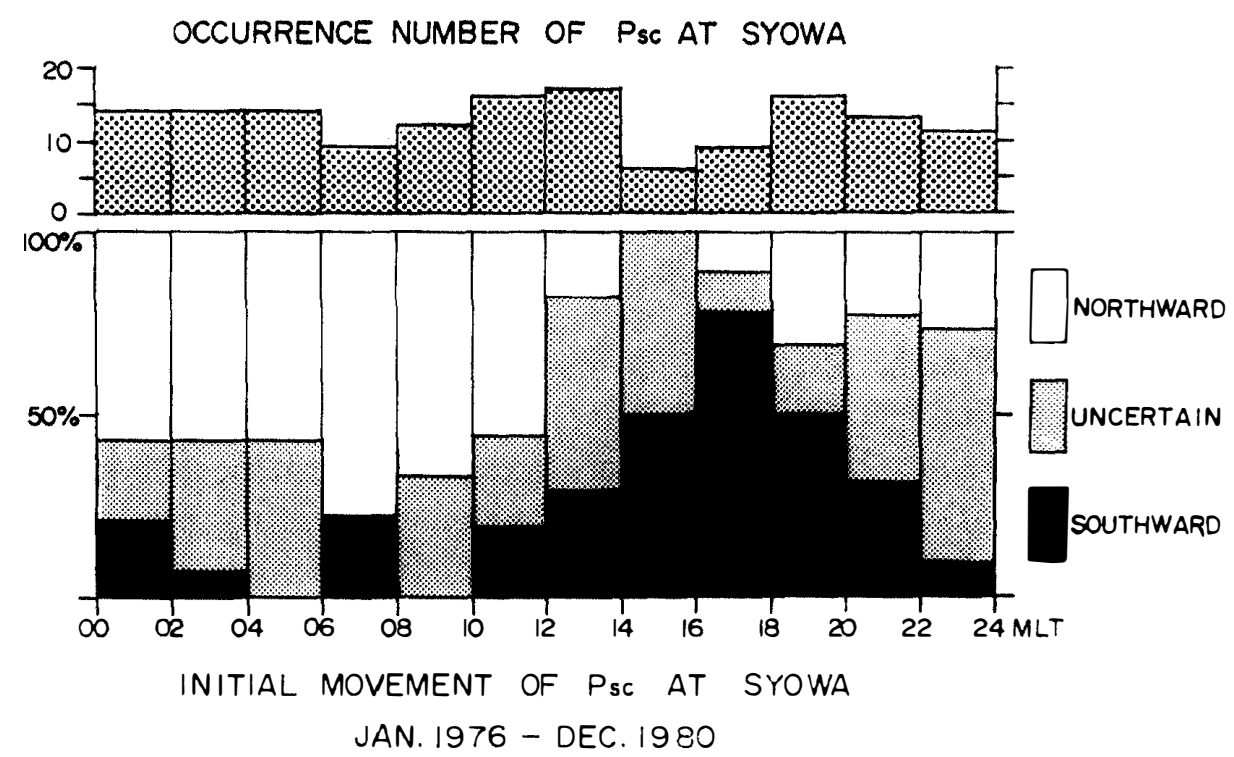

Fig. 9. The distribution of the direction of the initial movement of Psc at Syowa Station (L 6.1).

not similar to that at the satellite used in the present analyses (SMS-GOES whose LT is in a range from UT-5 to UT-9). Therefore, the one-to-one comparison of the initial movements between the satellite and Syowa Station will be meaningless. For this reason, the problem has been studied statistically in the present study. Examples of Psc observed at Syowa Station are illustrated in Fig. 8, where the SSC events which occurred in the morningside and in the eveningside are illustrated in the upper panel and in the lower panel, respectively. In the figure, the Psc oscillations are presented in the north-south component, because the oscillations are much more dominant in the north-south component than in the east-west component in the auroral region. Concerning the examples shown in Fig. 8, it is suggested that the direction of the initial movement is northward in the morningside (upper panel), while the direction is southward in the eveningside (lower panel) in the auroral region. The tendency has been studied statistically, and the results are summarized in Fig. 9, where the direction of the initial movement of Psc is presented using the coordinates of the occurrence probability and occurrence local time. As shown in the figure, it is confirmed statistically that the local-time dependence of the initial movement of Psc also exists in the auroral region on the ground as well as at the geosynchronous altitude in the magnetosphere. Before detected on the ground, the SSC signal must have propagated through the ionosphere. A less conspicuous local-time dependence on the ground (Fig. 9) compared with that in the magnetosphere (Fig. 7) might be related to the ionospheric modulation effect. The existence of the ionospheric effect is also suggested because the dominant oscillation is in the east-west component at the geosynchronous altitude (Fig. 5), while it is in the north-south component in the auroral region (Fig. 8). Those problems will be further discussed in Section 6 .

\section{Discussion}

One of the important evidences derived from the present analyses is the existence 
of the conspicuous local-time dependence of the amplitude of SSC at the geosynchronous altitude as shown in Fig. 2. The amplitude of SSC in the compressional component (parallel component to the ambient magnetic field direction) at the geosynchronous altitude is large in the noonside, while it becomes smaller with increasing distance from the noonside, and it is very small in the nightside. Especially in the midnightside (00-02 LT), the amplitude of SSC often decreases in association with SSC.

It is no doubt that the SSC phenomena are closely associated with the discontinuity of the solar wind velocity (shock wave). If the shock wave front is perpendicular to the sun-earth line, the magnetosphere is exposed to the post-shock solar wind from its apex toward the tail. Therefore, the magnetosphere adjusts itself to a new solar-wind condition from the previous condition. In other words, a new electric current will be established throughout the magnetosphere. If the magnetospheric cavity was empty, an enhancement of the solar wind pressure would give rise to a fairly uniform northward field (increasing the amplitude of SSC) within the magnetosphere and over the earth's surface. However, because the cavity is filled with thermal plasma, the propagation of the signal is complicated. Hydromagnetic waves of different modes are generated at the magnetopause. Their propagation is further complicated during the passage through the plasmasphere and the ionosphere as suggested by TAMAO (1964) and WILKEN et al. (1982). Such the situation mentioned above would be closely related to the local-time dependence of SSC at the geosynchronous altitude. ONDOH (1970) also reported the local-time dependence of SSC using the data obtained at OGO 3 and 5 which were located in the high latitudes in the magnetosphere. According to his results, however, the local-time effect is much less than that obtained from the present result. The signature of SSC could be still observable with a large amplitude nearly the same as that on the ground at the high latitudes in the nightside magnetosphere. Considering those results, the conspicuous local-time effect as is shown in Fig. 2 seems to be seen only near the equatorial-plane in the nightside magnetosphere.

In the midnight (00-02 LT), the SSC-associated field at the geosynchronous altitude often shows a southward change (decreasing the amplitude of SSC). That change will be also related to the complicated propagation of the SSC-associated hydromagnetic wave in the magnetosphere. Recently, KoKUBUN (1983) suggested that the decreasing event mentioned above might be related to the substorm-associated phenomena such as the current disruption of the cross-tail current or reconfiguration of the field-aligned system. These problems, however, are reserved for future studies.

The SSC signal is transmitted through the magnetosphere and down to the ionosphere. If the magnetospheric cavity were a vacuum, the SSC signal could reach the earth within $\sim 0.2 \mathrm{~s}$. However, the cavity is filled with thermal plasma, which is distributed inhomogeneously in the outer and inner magnetosphere, in the plasmasphere and in the ionosphere. Especially, the high plasma density in the plasmasphere might cause a retardation for the SSC propagation because of the lower Alfvén velocity in that region. It would be very useful if we could measure the arrival of the SSC signal at the various points in the magnetosphere by using multiple satellites. Though, such a measurement is impossible in the present study, the propagation 
velocity of SSC in the compressional mode may be estimated by studying the time delays derived from the propagation from the noonside to the nightside at the geosynchronous altitude. According to the present results shown in Fig. 4, a propagation time of 2-3 min is estimated for the propagation. The corresponding velocity is estimated to be $750-1100 \mathrm{~km} / \mathrm{s}$. These velocities are consistent with that reported by WILKEN et al. (1982) who measured the velocity $(\sim 910 \mathrm{~km} / \mathrm{s})$ by using multiple satellites. However, the velocities derived from the observational results (the present study and WILKEN et al., 1982) are a factor of 2 lower than that theoretically estimated (NISHIDA, 1978) for relatively undisturbed conditions. This would correspond to a plasma at the geosynchronous altitude with a mass density a factor of 4 to 5 above the quiet time level. According to the present result shown in Figs. 3 and 4, a propagation time from the geosynchronous altitude to the ground is estimated to be $600-700 \mathrm{~km} / \mathrm{s}$. This velocity is consistent with that theoretically derived by FRANCIS et al. (1959), $900 \mathrm{~km} / \mathrm{s}$, taking into account the uncertainties about the actual mass density and its radial distribution in the magnetosphere, in the plasmapause and in the ionosphere.

Table 1. Initial movement of Psc.

\begin{tabular}{lll}
\hline & Morningside & Eveningside \\
\hline Space $\sim 6.5 R_{\mathrm{E}}$ above equatorial-plane & Eastward & Westward \\
Ground $L \sim 6.1$ & Northward & Southward \\
\hline
\end{tabular}

In the present study, the very conspicuous local-time effect is also found in the direction of the initial movement of Psc both at the geosynchronous altitude in the magnetosphere and in its conjugate region on the ground. The observational results are summarized in Table 1. It should be noted that the geosynchronous satellite was located above the geomagnetic equatorial plane during the measurements. As shown in Table 1, it is strongly suggested that the major axis of the polarization of the Psc oscillation is rotated through $90^{\circ}$ in a propagation along the field line from the magnetosphere to the ground through the ionosphere. The ionospheric screening effect has been studied theoretically by many researchers (NISHIDA, 1964; TAMAO, 1964; InOue, 1973; Hughes and Southwood, 1976a, b). They have theoretically predicted that the major axis of wave polarization should be rotated through $90^{\circ}$ in a propagation from the magnetosphere to the ground through the ionosphere. According to their results, magnetic perturbations on the ground and in the magnetosphere should be represented by the following relation,

$$
\boldsymbol{B}_{\mathrm{NG}}=\frac{\Sigma_{\mathrm{H}}}{\Sigma_{\mathrm{P}}} \exp (-|m| d) \cdot \boldsymbol{B}_{\mathrm{EM}},
$$

where $\boldsymbol{B}_{\mathrm{NG}}$ is the magnetic perturbation on the ground in the northward direction, while $\boldsymbol{B}_{\mathrm{EM}}$ is the magnetic perturbation in the magnetosphere in the eastward direction. $\Sigma_{\mathrm{H}}$ and $\Sigma_{\mathrm{P}}$ are height integrated Hall and Pedersen conductivities, while $m$ and $d$ are wave number in the perpendicular plane to the reference magnetic field and altitude of the ionosphere, respectively. The relation (1) means that the northward (southward) component on the ground is produced from the eastward (westward) component in 
the magnetosphere. In other words, the magnetic perturbation vector is rotated through $90^{\circ}$ in the counterclockwise direction when viewed toward the ground in the northern hemisphere, while it is rotated through $90^{\circ}$ in the clockwise direction in the southern hemisphere. The existence of the $90^{\circ}$ rotation of the major axis of the Psc wave polarization means that an existence of a propagation of the Alfvén mode along the field line causing the hydromagnetic standing oscillation, because the abovementioned $90^{\circ}$ rotation can be deduced for only the Alfvén mode (HugHes and Southwood, 1976a, b). As mentioned above, the behavior of the initial movement of Psc can be interpreted by the SSC associated hydromagnetic disturbance with the Alfvén mode and its propagation to the ground along the field line through the ionosphere.

At the geosynchronous altitude, the direction of the initial movement of Psc is eastward in the morningside and westward in the eveningside as shown in Figs. 6 and 7. In other words, the initial movement of Psc is directed oppositely to the solarwind flow. According to the theoretical results by PidDington $(1959,1960)$, a frictional interaction between the enhanced plasma flow and magnetic field lines in the morningside and in the eveningside bends the field away from the sun. The current $\boldsymbol{j}$ associated with the interaction must flow into the magnetosphere in the morningside, while flow out of the magnetosphere in the eveningside. Therefore, the frictional force must be the Lorentz force $(\boldsymbol{F}=\boldsymbol{j} \times \boldsymbol{B})$ which is directed opposite to the solar-wind flow. It is strongly suggested that such a frictional force causes the initial movement of Psc as shown in Figs. 6 and 7. According to the results by PidDington (1959, 1960), the frictional force causes the twist (transverse) wave which propagates along the field line towards the ground with the Alfvén velocity. This transverse wave which has been predicted theoretically is confirmed experimentally as the Psc wave in the present study.

\section{Conclusion}

The SSC-associated magnetic phenomena in the magnetosphere have been studied using the data obtained at the geosynchronous satellites, SMS/GOES, as well as the data obtained on the ground. Very characteristic local-time dependencies are found for the SSC-associated magnetic phenomena at the geosynchronous altitude. In the compressional component, the amplitude of SSC is conspicuous in the noonside, while it becomes smaller with increasing distance from the noonside and is very small or none in the midnightside. In the transverse component, the direction of the initial movement of Psc changes drastically across the noon and the midnight. The direction is eastward in the morningside, while it is westward in the eveningside.

\section{Acknowledgments}

The authors wish to express their appreciations to Prof. A. Nishida of the Institute of Space and Astronautical Science for his encouragement during the course of the present study. The SMS/GOES data used in this paper have been obtained from the World Data Center A, Solar-Terrestrial Physics. 


\section{References}

AraKI, T. (1977): Global structure of geomagnetic sudden commencements. Planet. Space Sci., 25, 373-384

Araki, T. and Allen, J. H. (1982): Latitudinal reversal of polarization of the geomagnetic sudden commencement. J. Geophys. Res., 87, 5207-5216.

Arthur, C. W. (1979): SMS-GOES satellite position and data availability. NOAA Tech. Memo. ERL SEL-54, 7 p.

Burlaga, L. F. and Ogilvie, K. W. (1969): Causes of sudden commencements and impulses. J. Geophys. Res., 74, 2815-2825.

Chapman, S. and Ferraro, V. C. A. (1931): A new theory of magnetic storms. Terr. Magn. Atmos. Electr., 36, 77-186.

Chen, L. and Hasegawa, A. (1974): A theory of long-period magnetic pulsations, 2. Impulse excitation of surface eigenmode. J. Geophys. Res., 79, 1033-1037.

Francis, W. E., Green, M. J. and Dessler, A. J. (1959): Hydromagnetic propagation of sudden commencements of magnetic storms. J. Geophys. Res., 64, 1643-1645.

Gosling, J. T., Asbridge, J. R., Bame, S. J., Hundhausen, A. J. and Strong, I. B. (1967): Discontinuities in the solar wind associated with sudden geomagnetic impulses and storm commencements. J. Geophys. Res., 72, 3357-3363.

Grubb, R. N. (1975): The SMS/GOES Space Environment Monitor Subsystem. NOAA Tech. Memo. ERL SEL-42, 15 p.

Hughes, W. J. and Southwood, D. J. (1976a): The screening of micropulsation signals by the atmosphere and ionosphere. J. Geophys. Res., 81, 3234-3240.

Hughes, W. J. and Southwood, D. J. (1976b): An illustration of modification of geomagnetic pulsation structure by the ionosphere. J. Geophys. Res., 81, 3241-3247.

INOUE, Y. (1973): Wave polarization of geomagnetic pulsations observed in high latitudes on the earth's surface. J. Geophys. Res., 78, 2959-2976.

Kaufman, R. L. and WAlKer, D. N. (1974): Hydromagnetic waves excited during an SSC. J. Geophys. Res., 79, 5187-5195.

Kokubun, S. (1983): Characteristics of SSC in the magnetosphere. J. Geophys. Res., 88, 1002510033.

KuWAshima, M. (1972): Long period geomagnetic pulsations associated with storm sudden commencements (Psc 5). Mem. Kakioka Mag. Obs., 15, 31-45.

Kuwashima, M., Tsunomura, S., Kawamura, M. and Fununishi, H. (1984): SSC associated magnetic variations at the geosynchronous altitude. submitted to J. Atmos. Terr. Phys.

Matsushita, M. (1960): Sudden commencements of geomagnetic storm. J. Geophys. Res., 65, 1423-1435.

Nagata, T. and Abe, S. (1955): Notes on the distribution of SSC* in high latitudes. Rep. Ionos. Space Res. Jpn., 9, 39-44.

Namikawa, T. and Matsushita, S. (1970): Magnetospheric convections and damped type geomagnetic pulsations associated with storms. Planet. Space Sci., 18, 407-415.

NishidA, A. (1964): Ionospheric screening effect and storm sudden commencement. J. Geophys. Res., 69, 1861-1874.

NishidA, A. (1978): Geomagnetic diagnosis of the magnetosphere. New York, Springer, $256 \mathrm{p}$.

NishidA, A. and JACOBS, J. A. (1962a): Worldwide changes in the geomagnetic field. J. Geophys. Res., 67, 525-540.

NishidA, A. and JACOBS, J. A. (1962b): Equatorial enhancement of worldwide changes. J. Geophys. Res., 67, 4937-4940.

ObAYASHI, T. and JACOBS, J. A. (1957): Sudden commencements of magnetic storms and atmospheric dynamo action. J. Geophys. Res., 62, 589-616.

Ogilvie, K. W., Burlaga, L. F. and Wilkerson, T. D. (1968): Plasma observations on Explorer 34. J. Geophys. Res., 73, 6809-6824.

Ohnishi, H. and Araki, T. (1983): Ionospheric screening effect on the low-latitude SC. The 73rd 
Annual Meeting of Japanese Society of Geomagnetism and Geoelectricity, 222.

ONDoh, T. (1963): Longitudinal distribution of SSC rise times. J. Geomagn. Geoelectr., 14, 198207.

ONDOH, T. (1970): Magnetospheric sudden impuleses. J. Radio Res. Lab., 17, 199-212.

Piddington, J. H. (1959): The transmission of geomagnetic disturbances through the atmosphere and interplanetary space. Geophys. J. R. Astron. Soc., 2, 173-189.

Piddington, J. H. (1960): Geomagnetic storm theory. J. Geophys. Res., 65, 93-106.

Saito, T. and Matsushita, S. (1967): Geomagnetic pulsations associated with sudden commencements and sudden impulses. Planet. Space Sci., 15, 573-587.

SANO, Y. (1962): Morphological studies on sudden commencements of magnetic storms using the rapid-run magnetograms during the IGY. J. Geomagn. Geoelectr., 14, 1-15.

SANO, Y. (1964): Morphological studies on sudden commencements of magnetic storms using rapidrun magnetograms. Mem. Kakioka Mag. Obs., 11, 1-52.

Sugiura, M., Skillman, T. L., Ledley, B. G. and Heppner, J. P. (1968): Propagation of the sudden commencement of July 8, 1966 to the magnetotail. J. Geophys. Res., 73, 6699-6709.

TAMAO, T. (1964): A hydromagnetic interpretation of geomagnetic SSC. Rep. Ionos. Space Res. Jpn., 18, 16-31.

TAMAO, T. (1975): Unsteady interactions of solar wind disturbances with the magnetosphere. J. Geophys. Res., 80, 4230-4236.

Wilken, B., Goertz, C. K., Baker, D. N., Higbie, P. R. and Fritz, T. A. (1982): The SSC on July 29, 1977 and its propagation within the magnetosphere. J. Geophys. Res., 87, 5901-5910.

WiLSON, C. R. and Sugiura, M. (1961): Hydromagnetic interpretation of sudden commencements of magnetic storms. J. Geophys. Res., 66, 4097-4111.

(Received June 6, 1983; Revised manuscript received January 20, 1984) 